\title{
Megacystis-megaureter syndrome
}

INSERM

\section{Source}

INSERM. (1999). Orphanet: an online rare disease and orphan drug data base.

Megacystis-megaureter syndrome. ORPHA:238637

Megacystic-megaureter syndrome is an urinary tract malformation characterized by the presence of a massive primary non-obstructive vesicoureteral reflux and a large capacity, smooth, thin walled bladder due to the continual recycling of refluxed urine. Recurrent urinary infections are commonly associated with this condition. 